Article

\title{
Design of Dwellings and Interior Family Space in China: Understanding the History of Change and Opportunities for Improved Sustainability Practices
}

\author{
Adrian Pitts * and Yun Gao \\ Department of Architecture and 3D Design, University of Huddersfield, Queensgate, \\ Huddersfield HD1 3DH, UK; E-Mail: y.gao@hud.ac.uk \\ * Author to whom correspondence should be addressed; E-Mail: a.pitts@ hud.ac.uk; \\ Tel.: +44-1484-472281.
}

External Editor: Derek Clements-Croome

Received: 24 July 2014; in revised form: 19 October 2014 / Accepted: 21 October 2014 /

Published: 31 October 2014

\begin{abstract}
This paper reviews briefly the recent history of dwelling design in China. It notes the rapid changes that have taken place since the 1980s and identifies the way contemporary procurement processes leave out the final fit-out and decoration/refurbishment. A range of stakeholders were interviewed, and access was gained to drawings and other technical data that indicated how the secondary processes were carried out. These are largely ungoverned by regulation in the same way necessary for initial design. The key group is the occupants who drive the fit-out and decoration according to personal and cultural requirements, but often with less than perfect understanding of sustainability. The interior design industry has developed rapidly over the same period and was initially lacking in professional knowledge and understanding (something which can still be found). Advice provided to dwelling occupants was based more on appearance than function and efficiency. Over the same period, beneficial modifications to construction processes have been introduced in relation to structural design, and it should be possible to do the same for sustainability-related design issues. The paper advocates: more regulation; better assessment techniques; more information and guidance for home-owners; and a greater focus on energy issues.
\end{abstract}

Keywords: sustainable design; interior design; dwellings; construction; China 


\section{Introduction}

The purpose of the research underlying this paper was to consider how to promote opportunities for improvements in sustainability performance within the Chinese housing sector. Dwelling construction underpins the strength of the Chinese economy, and the rapid growth of housing construction has been remarkable in China with a rate of home ownership now exceeding 90\% [1]. The expectation for more urban dwellings and even more new construction continues. With such large volumes of new buildings still occurring alongside large numbers of interior fit-outs and refurbishments, it is vital that resource-efficient techniques and energy-efficient design are employed to avoid future difficulties and also to reduce global warming risk. Improved regulations at the national and provincial level have increased requirements for more sustainable use of energy and, to a lesser extent, other resources, but there is still potential for increased demand for energy. This arises because a key feature of dwelling production at the present time is the limitation of initial construction to almost a bare shell; this means that most systems and a number of key components are not installed, but rather left to future occupants. The fit-out (and refurbishment) of dwellings has potential to be wasteful of resources and to permit the installation of appliances and systems with poor energy efficiency or which are inappropriate.

As a result of this situation, the authors engaged in one of the first investigations of the current situation in China through the medium of an in-depth study in a mid-sized provincial capital city: Kunming. Plans and drawings were studied, not just from the initial design phase, but also from subsequent alterations and constructional changes. This was complemented by detailed interviews with a range of stakeholders in order to identify not just current practice and attitudes, but also to reveal the historic basis for current design and the timeline over which changes in construction of dwellings have taken place. The study considered how the roles of designers, developers and building owners have evolved in the process of the development of housing design since the 1980s. By interviewing architects, interior designers, property management officers and property owners and by analysing design development for housing design, the paper investigates how the combined effects of the government policies, building regulations and market forces have impacted the design of houses and, particularly, interior environments. It also attempts to examine how the concept of "sustainable building design" is perceived and understood in a contemporary Chinese city.

As mentioned above, the dwelling fit-out and/or refurbishment has fewer regulatory restrictions, and there is much potential for the waste of materials and less than optimal design, something that was particularly evident in information gathered from interviewees relating to the 1980s. Furthermore, because of residents' desires to maximize interior space, negative impacts on structural integrity were also discovered. The paper explores some of the scenarios and difficulties with reference to real examples of design modification gleaned from access to plans, though sometimes also reliant on sketches from dwelling occupants. The organization of family living space is an important issue leading to change. Over the timeline of the periods studied, it seems the lack of knowledge amongst those managing and implementing interior design changes was initially very high, and there remain some areas of concern, which are discussed.

This paper therefore consists of several different interwoven themes: that of the history and evolution of dwelling design, construction and use (particularly in the period since 1978); that of the importance and impact of interior design in the whole system; and that of the potential of the current methods of design and construction to influence, both positively and negatively, sustainability and energy efficiency. 
It is vitally important in considering ways forward that the influencing factors and actions that have led to the current state of play are understood. The paper concludes by making recommendations for changes to information availability, changes to practice and regulation and a change in the current construction market to a greater focus on standards for the post-completion stage of the dwelling life-cycle.

\section{Outline of Historical Context}

This section deals with the historical development of housing policy, which has accompanied both rapid urbanisation and economic change in China in the last five decades. It considers specific elements that were revealed as having impact following stakeholder interviews. It is important to link the housing situation before 1949 through the developments in the 1980s and 1990s to the much changed situation to be found in the present day.

After the establishment of the People's Republic of China (PRC) in 1949, the country followed a highly centralized economic system based upon the Soviet model. The central planning departments made decisions on the distribution of national income and welfare benefits, and public housing was made available to individual families as a form of welfare provision [2]. In this period, political influences produced a somewhat uniform and almost identical built environment. Housing design was based on principles of building economical and functional accommodation to meet basic needs. As a result, newly constructed indoor and outdoor residential environments appeared monotonous, even across different regions, and aesthetic aspects of design that had been prominent before this period were largely lost or ignored.

Important changes in urban planning policies and the promotion of housing construction were proposed by the government in 1978. Housing ownership and the procurement process reform was identified as the solution for the serious housing shortages in the country. The commercialisation of urban welfare-oriented housing started with pilot projects in Guangzhou and Shenzhen in 1981.

From 1995 to 2003, China introduced market mechanisms and established the urban housing market. A dual housing provision system was created, comprising a social housing sector of "economical and comfortable housing" for low and middle income urban households and a "commodity housing" sector targeting higher-income groups [3]. According to the data issued by People's Bank of China in 2002, before the reform, $80 \%$ to $90 \%$ of housing investment came from government or state-owned enterprises. It decreased to less than $50 \%$ after 1995 , and by 2001 , around $80 \%$ of homes in urban China were privately owned [4]. In China's large cities, the housing structure effectively entered an era of full homeownership by 2005 .

It is clear that a series of significant reforms and developments took place in Chinese cities in the period from the mid-1980s onwards: the marketisation of state-owned enterprises; the commoditisation of the housing sector; and reforms of the land system and land market [5]. Facing simultaneously rapid urbanisation and an evolutionary process of urban housing commercialisation, much research was carried out to analyse the nature and dynamics of the urbanisation process and of residential developments (for example, [6-8]). This indicated that one of the problems caused by the rapid urbanisation process was a lack of sustainably designed residential houses.

In contrast to Western countries, the peculiar and particular situation in residential development in China is the result of the combined effects of the privatisation of the property market and the persistent influence of the socialist legacy; it should be noted that land in cities and towns remains in the ownership 
of the state $[9,10]$. The relationship between designers, developers and property buyers in China operates in a very different way to those in Western countries; the majority of newly completed residential dwellings in China require re-design and re-decoration by the property owners to make them habitable and fit for function and purpose. The re-design processes bring with them the potential for a substantial waste of materials and labour and a propensity to design dwellings with less concern for energy efficiency.

\section{Research Methodology}

The principal methods of investigation used in this study were group discussions, interviews with stakeholders and the study of drawings and relevant documents for apartments designed and built in the periods of the 1980s, 1990s and after 2000. This approach is quite novel for this topic area in China, and any information gained would have value. Rather than attempt to interview a large number of people with the inherent difficulties of the system and access to residents, it was concluded that more focused, but in-depth, interviews would gather the most useful information.

An initial scoping study was carried out through discussion with approximately 20 academic staff at a university in the city where the majority of detailed interviews would be located and also with a similar group of residents from a typical residential district. In addition, and in order to verify the broader context, occupants of apartments in another neighbouring province were also interviewed and their apartments studied. The purpose of the study was to scope for the general characteristics of the second phase of the interior design process and, thus, the relevant interrogation issues for interviews with sixteen stakeholders (a mixture of property owners, architects, developers and interior designers). The interviewees were selected using local contacts to provide a breadth of potential contributors from which a cross-section was chosen; eleven of the interviewees had experience living in other cities and in varying climatic conditions. The choice was in part driven by a need to obtain detailed views from several who had wide experience of the period of change since 1978, though the age of the interviewees ranged from 18 to over 80 . There were ten male and six female respondents, and the interview typically lasted two hours.

Semi-structured interviews were used as the most direct and practical means to gather data on the participant stakeholder's perceptions of the dwellings and of sustainable design. This allowed some self-analysis for the interviewees who were asked to describe their views on, and decisions about, interior refurbishment and to reflect on what they would do if they were to be involved in the re-design of the interiors again. These interviews also identified many design decisions that were not normally documented in the design and construction processes, for example the decisions to change the structure in order to accommodate the second stage re-design and decoration by the users. Table 1 provides the key information about each interviewee.

All of the interviews were carried out by a local researcher in conjunction with one of the authors, who oversaw the process. There were no apparent translation issues, and the recorded interviews were transcribed and analysed using both a priori and emergent codes. 
Table 1. Summary of interviewee data and views on sustainable/green design.

\section{Information on Interviewees: \\ 1. Summary of Personal Data;}

\section{Apartment Size;}

3. Year Apartment Fitted-Out or Last Refurbished;

Summary of principal interviewee views on sustainable or green design

\section{The Cost of Fit-Out/Refurbishment in $¥$ Chinese}

Yuan (10 Yuan = GB £1 or U.S. \$1.6, approximately)

1. Interior designer, male, age group: $40-50$;

Sustainable design should emphasize/focus more on design and construction

2. $140 \mathrm{~m}^{2}$ apartment;

from a professional standpoint, so as to reduce waste. The waste not only

3. 2012 ; occurred when the owners demolished partition walls and changed the layout

3. 2012; of the rooms in new housing, but also occurred when they designed the interior

4. Cost: $230,000 ¥$ without an understanding of the functions of the rooms and when they incorrectly installed facilities, which led to further waste.

1. Property developer, male, age $40-50$;

2. $170 \mathrm{~m}^{2}$ apartment;

This means a good quality of construction. Use of devices, such as solar

3. 2012; panels. Provision of good natural light.

4. Cost: $200,000 ¥$

1. Student, male, age group under 20;

2. $120 \mathrm{~m}^{2}$, parents' apartment;

3. 2011;

4. Cost: $100,000 ¥$

1. Financial company manager, male, age $30-40$;

2. $150 \mathrm{~m}^{2}$ apartment;

3. 2012;

4. Cost: $300,000 ¥$

1. Government officer, female, age 50-60;

2. $150 \mathrm{~m}^{2}$ apartment;

3. 2012;

4. Cost: $250,000 ¥$

1. Direct of a computer company, male, age $40-50$;

2. $150 \mathrm{~m}^{2}$ apartment;

3. 2012;

4. Cost: $250,000 ¥$

1. Baker, male, age 40-50;

2. $140 \mathrm{~m}^{2}$ apartment;

3. 2012;

4. Cost: $150,000 ¥$

1. University lecturer, female, age 30-40;

2. $100 \mathrm{~m}^{2}$ apartment;

3. 2011;

4. Cost: $100,000 ¥$

1. Engineer, male, age 30-40;

2. $150 \mathrm{~m}^{2}$ apartment;

3. 2011;

4. Cost: $150,000 ¥$
Production of less air and water pollution; provision of more green space in the city; better ventilation and fresh air in the housing. Saving energy by using solar panels. Design for flexibility to change the apartment in the long term. New design options and new technologies that help with the environment.

Energy-efficient facilities. Good quality design of the building structure.

Clean (unpolluted) environments with plenty of green plants that can help provide fresh air. Organic paints and furniture/fabrics that do not produce poisonous emissions.

Design and products that are beneficial to the environment, which can be created by using advanced technology and contemporary design concepts.

Organic paints that have no poisonous emission are ideal, but those are so expensive that they are beyond a normal person's financial affordability.

Design should give more consideration to the quality and location of the fixed furniture and facilities, as they cannot be easily replaced if there is a problem or need for upgrading. Comfort in use and function should take priority over appearance.

Energy saving appliances and facilities. Good orientation to accept plenty of sunlight. High quality of construction. 
Table 1. Cont.

\section{Information on Interviewees:}

1. Summary of Personal Data;

\section{Apartment Size;}

3. Year Apartment Fitted-Out or Last Refurbished;

Summary of principal interviewee views on sustainable or green design

4. The Cost of Fit-Out/Refurbishment in $¥$ Chinese

Yuan (10 Yuan = GB £1 or U.S. \$1.6, approximately)

1. Shares manager, male, age 30-40;

2. $120 \mathrm{~m}^{2}$ apartment;

The home environment and public spaces should be free from pollution and

3. 2010; with plenty of green spaces and trees.

4. Cost: $80,000 ¥$

1. Retired university lecturer, female, age 70+;

2. $90 \mathrm{~m}^{2}$ apartment;

3. 2010;

4. Cost: $60,000 ¥$

Plenty of fresh air and natural light at home, ideally with green space to separate from the main streets to reduce air and noise pollution. Solar panels to provide hot water, and save energy.

1. Home-maker, female, age $40-50$;

2. $120 \mathrm{~m}^{2}$ apartment;

Interviewee was unsure what the terms meant. Perhaps a healthy environment

3. 2009; without air pollution or food pollution.

4. Cost: $85,000 ¥$

1. Factory worker, male, age 40-50;

2. $120 \mathrm{~m}^{2}$ apartment;

Energy efficient through the extensive use of air conditioning units during the

3. 2008; summer and winter. Less air, water and food pollution.

4. Cost: $90,000 ¥$

1. Architect, male, age 50-60;

2. $50 \mathrm{~m}^{2}$ apartment;

Energy efficient design with optimized use of land, energy and water. Good

3. 2006; thermal design and use of renewable energy.

4. Cost: $150,000 ¥$

1. Government officer, female, age 30-40;

2. $120 \mathrm{~m}^{2}$ apartment;

Healthy living environment with natural light, fresh air. Close to nature with

3. 2000; nearby green space.

4. Cost: $80,000 ¥$

1. Retired community manager, female, age 70+;

2. $110 \mathrm{~m}^{2}$ apartment;

3. 1990 (designed according to work units);

4. Cost: $30,000 ¥$

An environment with less water and air pollution. Better quality housing that is close to nature (close to a clean river and surrounded by woods, as now, the river is polluted with some sections dried up).

The $a$ priori codes related to residents were:

- Current living situation (information about the occupants and the dwelling — size and location, etc.);

- Methods of design and construction;

- Views on "green" building and sustainable design;

- Changes made to the apartments;

- Views about the internal environment relating to air quality, lighting, ventilation, noise and materials;

- Their intention and decisions and the process of the interior refurbishment; and

- Their reflection on the decisions made in the past by reviewing the experience of living in the apartment. 
The questions to the architects and developers related to:

- The process of design development;

- Methods of design and construction they have experienced;

- Views on "green" building and sustainable design;

- Changes made to apartments with which they were involved;

- Views about the internal environment related to air quality, lighting, ventilation, noise and materials;

- The impact of polices and building regulations; and

- The design decisions made in the process of procurement and construction and in fit-out and refurbishment with which they were involved.

As the interviews progressed, further emergent codes were added to examine how residents understood the concept of sustainable design and how their understanding led to different actions in relation to sustainable design. Emergent codes for developers related to the study of design decisions relating to the profits and management of the property. Emergent codes for architects and interior designers explored how the commercial interior design methods were adopted in private homes and design changes related to the new building regulations. In addition, apartment plans for buildings designed and built in the 1980s, 1990s and 2000 were analysed and compared.

The questions arising from the interviews and which informed further development of the study were as follows:

(1) What elements and factors influence people's decisions on interior design?

(2) How can behavioural and attitudinal change influence sustainable building design in the local social and cultural context?

(3) How have building regulations affected residential design since the 1980s?

(4) How can building regulations be modified to enforce more sustainable interior design?

\section{Housing Form Development and Impacts on Sustainability}

Historically, in most Chinese climates, the indoor and outdoor environments had great influence on people's residential life patterns and incorporated some understanding of sustainability concepts and measures through having to live within the means available. In many cities, the historical urban fabric was dominated by courtyard houses and pitched roof buildings. In some climates, plants and water features were used in courtyards to adjust the temperature and humidity of the micro-climate for both indoor and outdoor spaces (Figure 1). Within the compound, doors to rooms tended to open into the courtyard to provide natural light and ventilation when suitable. The courtyard also provided a space for daily family activities. It should be recognised that before the advent of air conditioning systems and when dwellings had only relatively unsophisticated heating systems, that they had to be designed to match with the climate and, thus, had a number of inherently sustainable design features.

A number of the interviewees reflected on their memories or understanding gained from family members of the changing form of dwellings over a 60-year period. After 1949, with the increasing urban population, a majority of existing courtyard houses became properties assigned to "work units" that were established under the new political regime. These were allocated to families as part of the welfare system. In most cases, each of the old courtyard houses was occupied by several families. 
Figure 1. A courtyard house in Kunming.

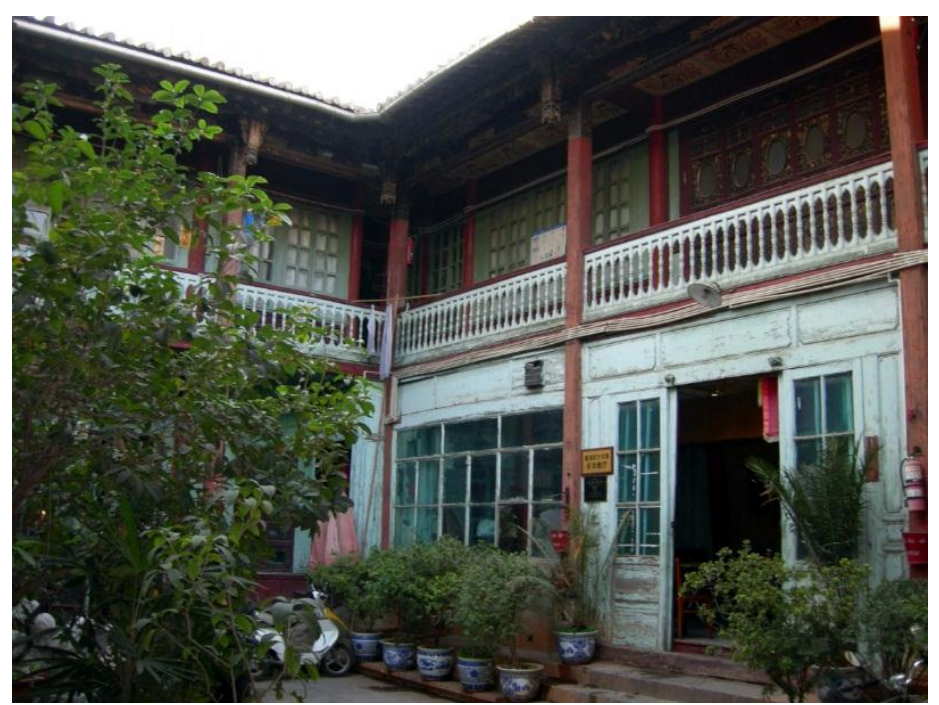

Interviewees recalled that in the courtyard houses, previous living rooms or bedrooms needed to be transformed into kitchens and other room types for each family, and small extensions were added in the courtyard to provide more space. All of the families' shared communal toilets and waste disposal areas. Eventually, the courtyard houses became increasingly dilapidated and overcrowded, with many families sharing the small space and lacking suitable cooking and hygiene facilities, as well as privacy. These factors help establish a background of experiences and expectations against which more recent practices should be judged. As a result of the problems, newer styled multi-storey apartment buildings were introduced and provided alternative solutions to meet the housing shortage.

In the 1980s, in Kunming (as with many cities), a large number of new residential neighbourhoods were built in a relatively short period. However, many of these new apartment zones still lacked sufficient public facilities and spatial qualities due to the strict controls still then in place and reflected in housing area standards. The standard set by the state in 1977 was $26-34 \mathrm{~m}^{2}$ per household (36-40 $\mathrm{m}^{2}$ in cold areas). In 1978, these were raised to $42 \mathrm{~m}^{2}$ per household [11]. To improve efficiency, housing design had to focus on higher ratios of usable space; as a result, some changes to floor plans resulted in long external corridors, single staircases to serve four or even eight families, corridor-style kitchens and shared toilets. Many multi-storey apartments were simple slab blocks set in a row. Interviewees mentioned two typical characteristics found in the design of the apartments: a southerly orientation and narrow depths in the plan of the main spaces. This meant that south facing rooms would be warm in winter and kept cooler in summer by use of shade and ventilation. Rooms facing west would be hot in the afternoon in summer, so buffer spaces, such as kitchens and toilets, might be allocated in those directions. These factors also affected the overall internal spatial arrangements.

The second characteristic identified above was a relatively narrow depth (at the end of the 1970s, standard housing block depth in China was between 8 and $10 \mathrm{~m}$ [11]). The reason for such a modest depth was the specified standard of useable floor space per unit: rooms were small, and increasing the depth would effectively have reduced the width of each dwelling and the rooms within it. Fortunately the modest depth meant that natural light and natural ventilation was available. Following the change in the building regulations that enlarged the useable areas, many residential buildings increased in depth, but also lost some potential for use of daylight and cross-ventilation. 
When large-scale housing development got underway in the country, more architectural input in a professional role and with understanding of the regulations was required for the design of residential areas. This was partly to address access to sunlight and housing density (as reported by interviewees involved in the procurement process). At this time, apartments were generally designed in a row with one staircase serving two apartments; each pair of units followed by other paired units in a row. The structural design was of a skeleton type with a range of load-bearing walls. The buildings were normally six to eight stories high to avoid the need for a lift in order to save costs (Figure 2).

Figure 2. Typical narrow-depth residential housing.

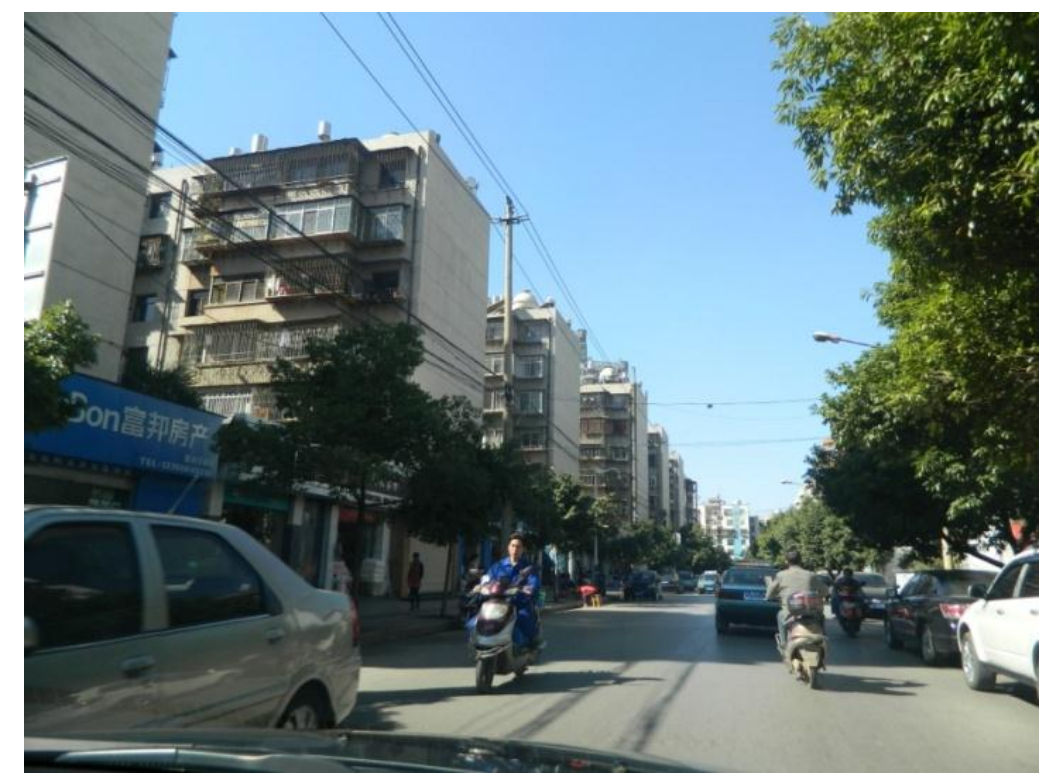

In different parts of China, it appears that diverse planning techniques were used through the grouping of differently-shaped housing units and through the manipulation of height and length in order to shape the outdoor space [12]. In some cities, the narrow depth of the residential buildings did not change until after 2000, when the height of apartment buildings increased significantly, and therefore, deeper plans were needed to ensure the structural stability of the blocks. It is therefore evident, and noted by several interviewees, that structural changes outside their control have impacted on the plan, layout and interior environmental character of apartments. The authors note that these factors would clearly also have affected energy performance and sustainability.

By 2000, diverse housing products were being designed and constructed for different social groups, including: subsidised housing; ordinary commercial housing; and high-quality luxury housing. The planning of some new residential districts began to be more varied, and some adopted the principles shown by traditional Chinese design, with housing arranged around communal gardens, rather than being lined up in rows. Different designs and styles of housing, such as split-level floors, semi-basements and double-height living rooms, were also being adopted.

The authors' investigations of previous research show two aspects. On one level, studies have already been carried out to research how technology can support sustainable residential development, such as the weighting of indicators of energy efficiency in residential buildings. These activities also included assessing indoor environment criteria, such as humidity, temperature and ventilation for residential houses developed in different climate zones in China [13-15]. On another level, research has considered macro-aspects of 
China's housing policies [16], the role and coalition of local government and developers [17] and also housing consumption $[4,10,18]$. However, a significant number of factors relating to the understanding and perception of sustainable design have been insufficiently explored. It seems that even when it was considered, over-generalised diagnosis using sustainable design or assessment criteria from developed (usually Western) countries has occurred. This took place without considering the way in which housing has developed in China and the roles certain stakeholders can play.

\section{Interior Design Issues}

The paper now turns to the issue of the initial and subsequent modifications to the design of the interior spaces in apartments. This focus arises from the comments made by the participants in the scoping study, as well as in the detailed interviews. The majority of older interviewees in the study confirmed that apartments occupied in the 1980s were originally constructed and owned by work units and later modified to more modern lifestyles. However, most of the younger interviewees had experience with more recent housing built as new residential compounds to fulfil the needs of the changing housing market.

The apartments in districts built from the mid-1980s onwards had generally been provided with only the minimum possible interior finishes, such as wall paint and bare concrete floors. Facilities in the kitchen and bathroom had been very limited or non-existent. The majority of new residential properties experienced or designed by the interviewees needed fit-out and re-decoration to make them habitable.

The interview data from both designers and residents highlighted two main reasons why property owners modified their homes after moving in the apartments. First, much of the early housing that had been developed by the work units was built based on principles of minimal cost, rather than value to the occupant; and secondly, the spatial arrangements had little consideration for the functional needs of daily life. Figure 3 illustrates a typical apartment layout before any intervention by the occupants.

Figure 3. The plan of the apartment before modification.

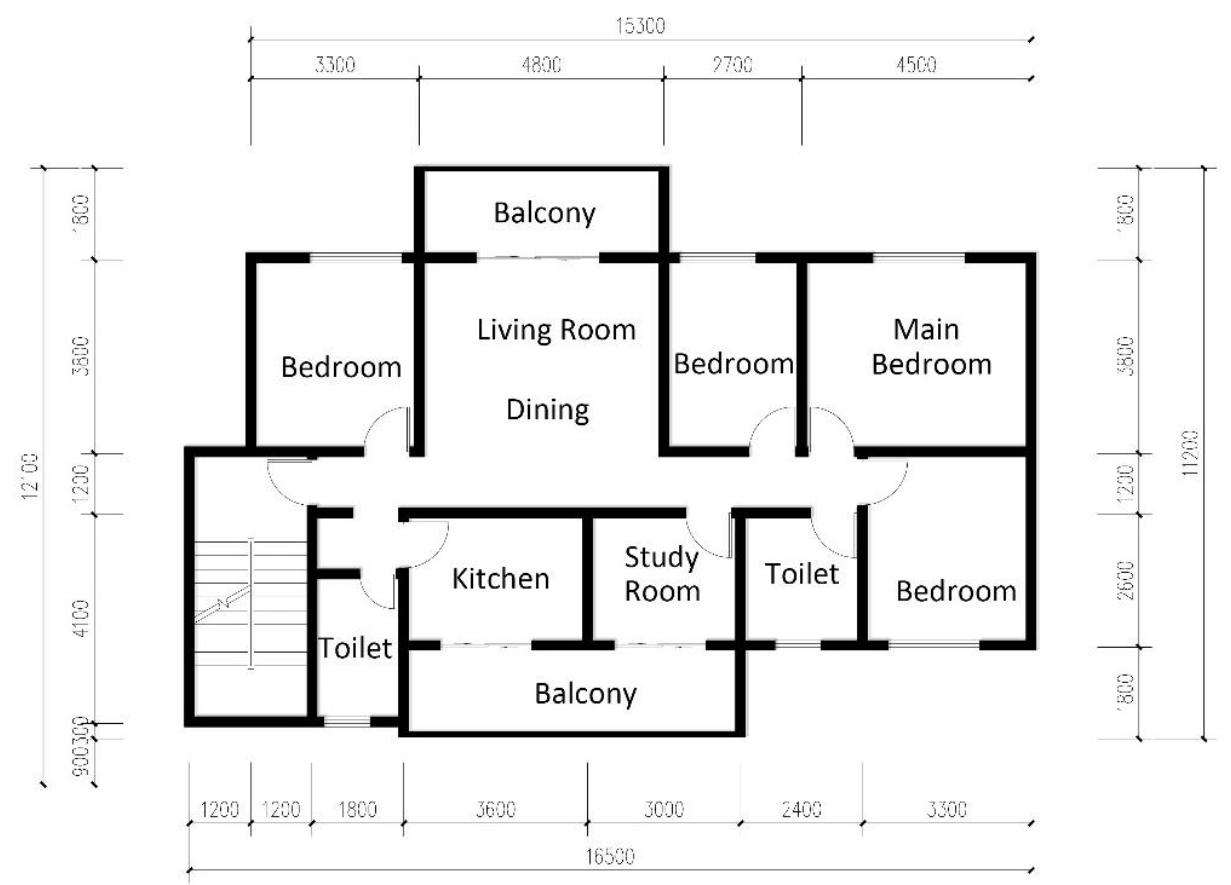


One of the reasons that occupants engaged in changes (both structural and decorative) was to create a more personalised living environment and one not based upon the restriction that had been in place with the former welfare housing model. More than half of interviewees said they carried out refurbishment as a second design phase to re-organise and make the most of the existing internal space. These changes typically involved removal of some walls and incorporation of the balconies into the interior living space, an example of which is seen in Figure 4.

In Figure 5, the photograph shows how the living room has been modified; the change in ceiling level shows the position of the former balcony. In other cases, separate new indoor spaces were created, as can be seen in the photograph of Figure 6.

Figure 4. The plan of the apartment after modification.

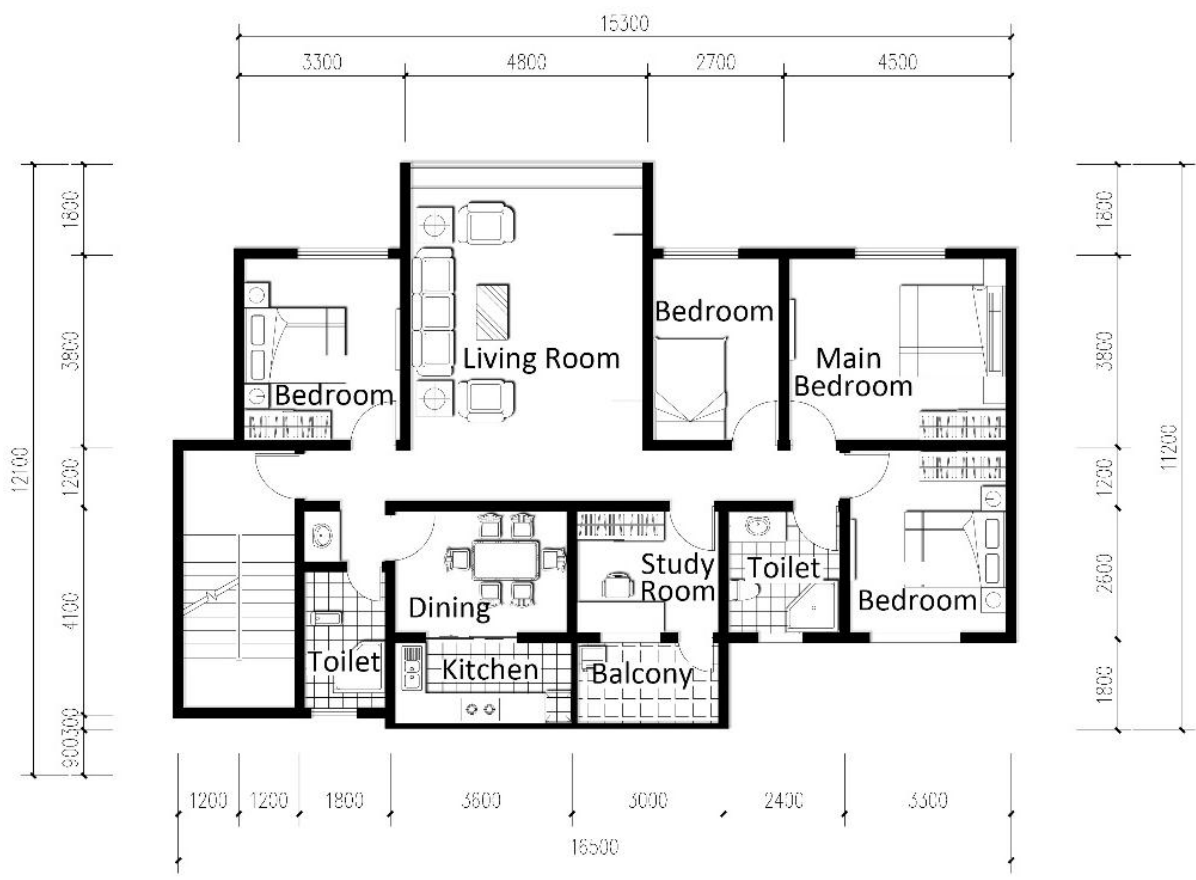

Figure 5. The balcony as part of the living room.

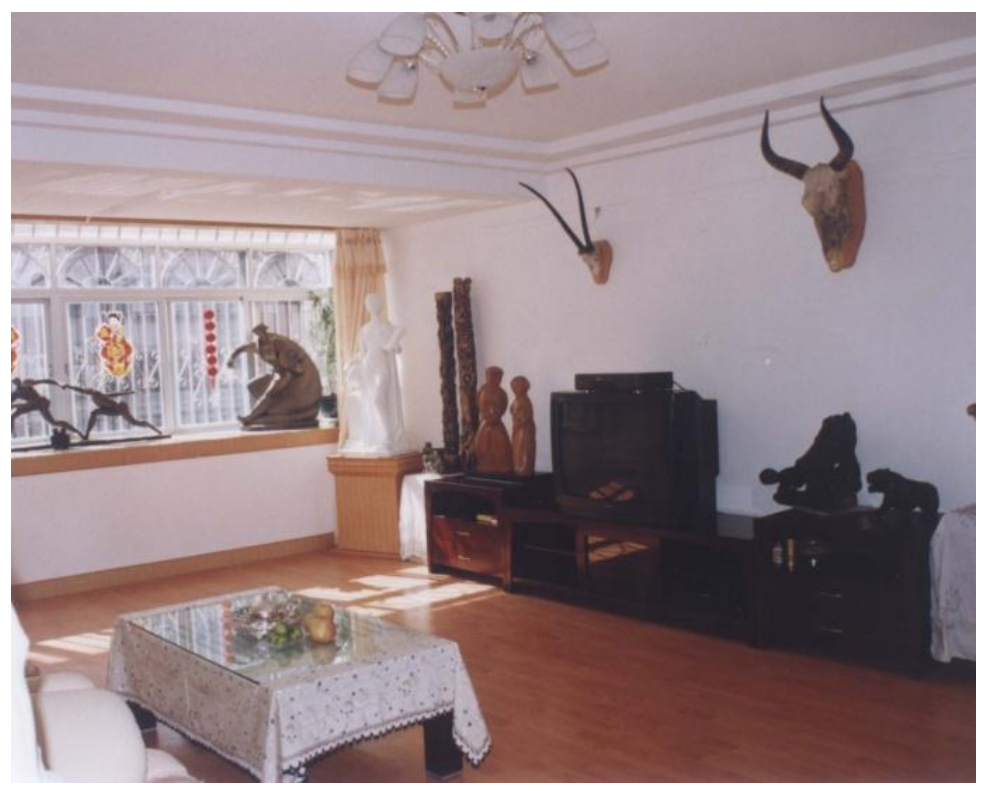


Figure 6. The balcony enclosed as a separate internal space.

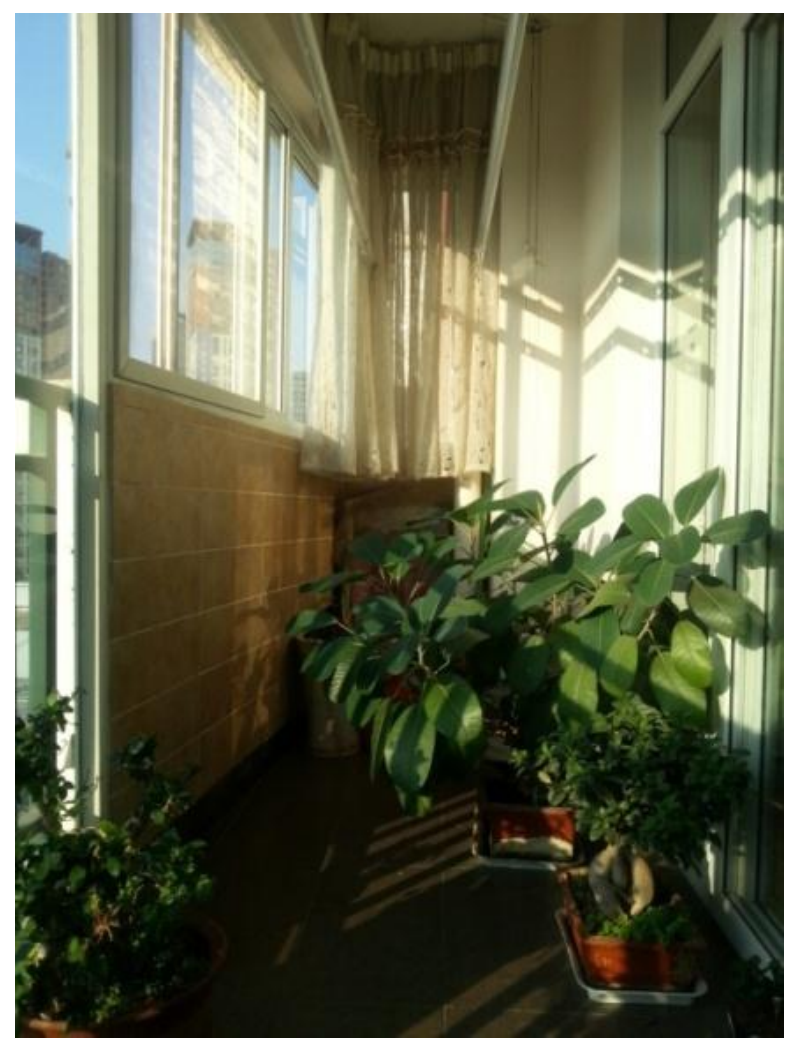

The majority of interviewees also commented that that they considered that the size of some rooms in the apartments had been rather small; this included dining rooms, kitchens and bathrooms, as well as living rooms. As a result, they tended to use each space for more than one function: for example, if the living room was too small for entertainment and meeting guests, those activities might be transferred to a bedroom. Lack of useful dining space also led to eating in the living room or in the kitchen. New household equipment that became more widespread in the 1980s also caused further space shortages - refrigerators and washing machines were reported as often being located in the living room. The majority of apartments had only one service balcony, which was mostly used as additional storage space. Interviewees also reported that staircases, landings and kitchens were also used as storage spaces. It should be noted at this point that most families had not been restricted to the "one-child" policy (introduced in 1979 and applied with various exceptions) and that multi-generational living (or at the very least, space for close family to come and stay) was common.

\section{The Development of the Interior Design Industry}

In relation to the design and construction of new apartment blocks (and as has already been identified), more and more occupants modified structural components (mainly walls), services and finishes. This led property developers to seek opportunities to maximise profit by excluding almost all of the now potentially deemed non-essential facilities or finishes formerly installed in new properties. As a result, by the 1990s, the majority of properties available for sale in all regions in China had no finishes to the walls and floors, and no kitchen/bathroom facilities. Any elements that were likely to be upgraded later were left out, including the internal doors and even internal staircases. 
For a long period dating from the late 1980s, plain housing design with no finishes became a common format for purchase by all income levels. The Chinese term "Zhuan Xiou" (install and build) evolved to refer to interior decoration, though actually meaning "to install the basic facilities and paint the surface of the walls and ceilings". In other words, buyers with little experience or skill in design or construction needed to install other facilities and complete the finishes of the apartment themselves. A photograph of an unfinished apartment can be seen in Figure 7.

Figure 7. A room in a basic apartment with no systems, appliances or finishes.

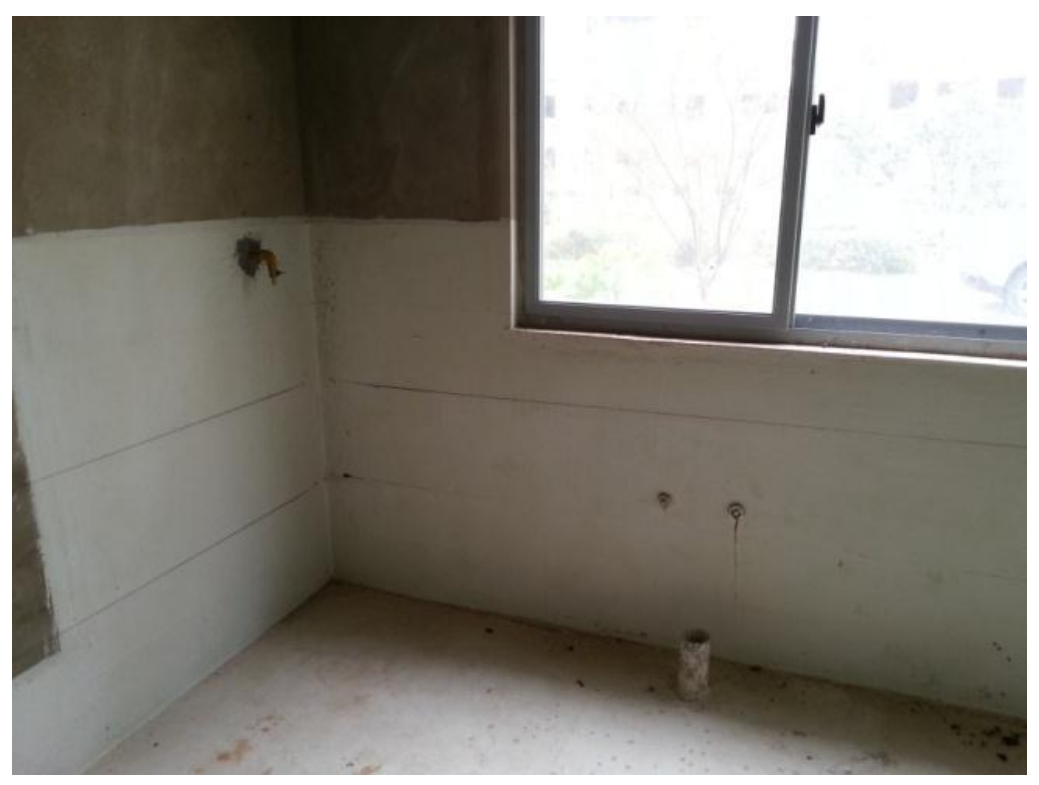

In the 1990s, large areas of Chinese city centres were rebuilt, and this coincided with a greater exposure of Chinese citizens to external ideas from such things as international exhibitions and access to the media. These had profound impacts on design sensibilities and desires [19]. It became clear in the interviews and group discussions that householders generally treated the interior space of the apartment differently from the physical structure of the building or the residential district. The building framework and the public areas (such as the communal garden, the staircase and the external surrounding land) were considered as publicly-shared property, whereas the interior space within the apartment was treated as "home". This could and should be managed and decorated according to personal preference without external interference. It was clear that great effort and substantial financial commitments had been allocated to the interior decoration by the interviewees; typically, this was of the order of a full year's salary.

This phenomenon also, to some extent, reflected the separation of the private ownership of the apartment and the state ownership of the land, which was something that was generally different from the Western context. In China, despite property owners having ownership of the apartment, the land is always rented on a lease. Developers and property owners can only obtain certificates for the right to use the land for 70 years for residential purposes; by comparison, it is 40 years for commercial use and 50 years for other uses.

The interviewees explained that the rise in demand for the interior refurbishment of residential properties quickly created an independent interior design and construction sector, because of the lack of knowledge and experience of apartment owners themselves. This new sector was quite separate from 
the Public Design Institutes (and their knowledge of architecture, design, construction and regulations), which had generally been (and continue to be) responsible for all building design in China. Interviewees reported their understanding that before the reforms to housing design and construction processes, there were no professional design and construction teams working on interior decoration for private housing, because all of the residential properties were part of the public sector and, thus, dealt with by the Design Institutes' staff. Therefore, when people were first able to buy their properties, in order to fit-out and decorate them, they had to make decisions themselves on design and then find craftsmen who had some knowledge of construction or decoration to carry out the work. Interviewees also reported that it was common for this new class of designer to borrow ideas from the public media, such as books and images from TV programmes, and, then, to make approximate choices from the limited palate of materials and facilities that were available in the marketplace. The result seems initially to have been a rather amateur and haphazard process with little regard for consequences associated with sustainability and environmental design.

By 2000, however, specialist interior design companies that could design, construct, decorate and refurbish private homes began to proliferate in response to market demand. They slowly began to provide their clients with a full range and catalogue of decoration materials and styles and associated with different levels of price. Property management companies were also formed and made responsible for the management of each residential district.

In certain circumstances, the original developers reacted quickly to these changes in the market and, in two cases identified by those associated with this study, demonstrated positive collaboration and improvements between developers, architects and property management companies. In particular, they had to address the safety issues that began to arise from occupants and interior designers with little or no understanding of structural issues making modifications to the walls.

The first improvement was to change the elements of a load-bearing structure that were likely to be removed in the interior refurbishment by the property owners. Both architect and developer interviewees were aware of the situation in which load-bearing walls were demolished in order to change the spatial arrangement in the interior fit-out and decoration phase. In the interviews, one architect recalled that in the discussion of the plan, both the developers and architects had specifically asked for load-bearing walls between the balcony and internal space to be relocated. Therefore, over a period of time, the structure of the buildings began to be changed to accommodate the requirements. On the plans in Figures 8 and 9, the walls that are load-bearing or non-load-bearing between the balcony and indoor space were clearly noted. Structural design was also updated to permit many of the internal walls to be defined as non-load-bearing, which also allowed the thickness of these walls to be reduced. Party walls between apartments and external walls, however, were not altered in order to maintain the thermal insulation and sound proofing qualities.

The professionals interviewed confirmed that as a consequence of these issues, not only were the regulations for the design of the initial structure changed to prevent the risk of demolishing load-bearing walls, but management rules for the properties were also developed to reduce the risk of structural problems occurring in the fit-out and decoration process. Each residential district had its own property management company that dealt with communal events and the safety of the district, such as organising the reception staff at the entrance gates, cleaning public areas, maintaining communal gardens and 
facilities, etc. Households living in the district already paid a monthly management fee to the company based on the size of the property.

Figure 8. Walls between balconies and the living room and dining room redefined as non-load-bearing walls.

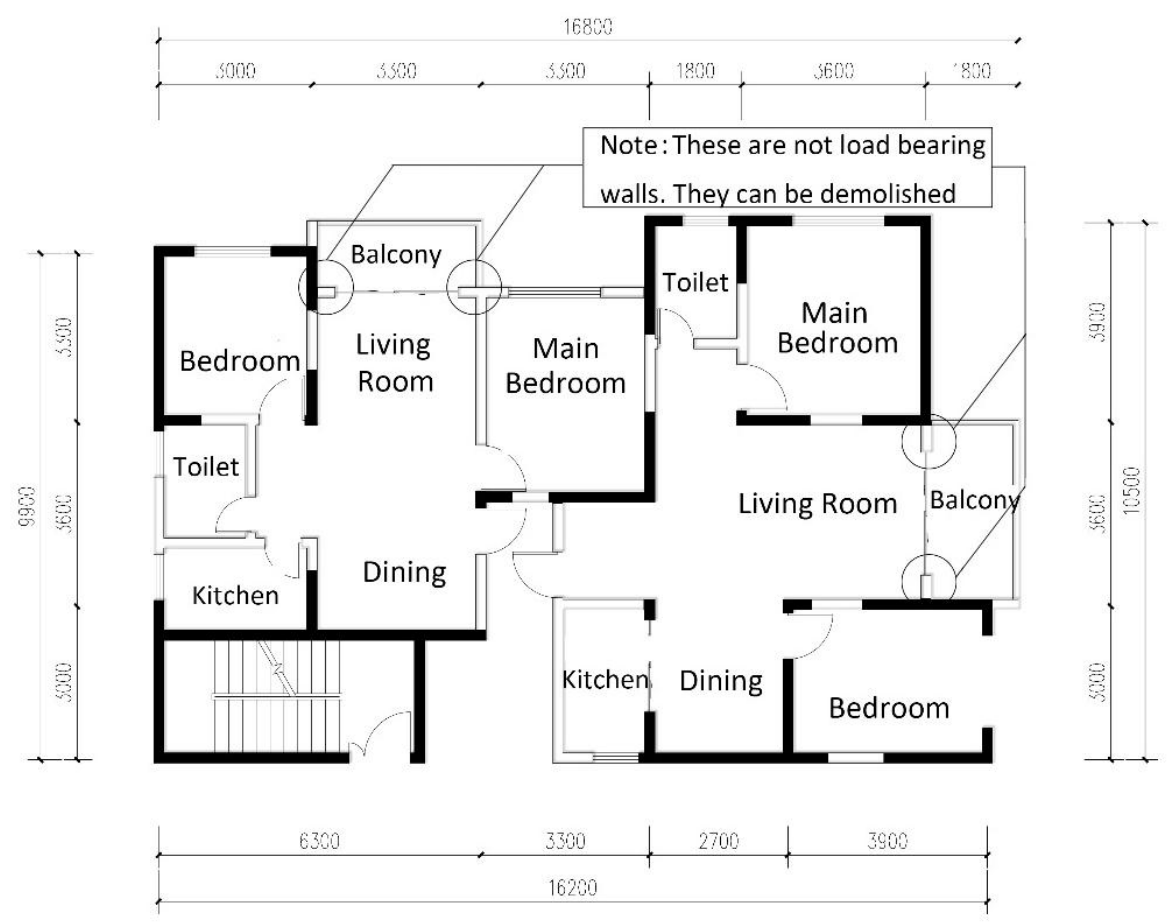

Figure 9. Walls between balconies and the living room, bedroom and dining room redefined as non-load-bearing walls.

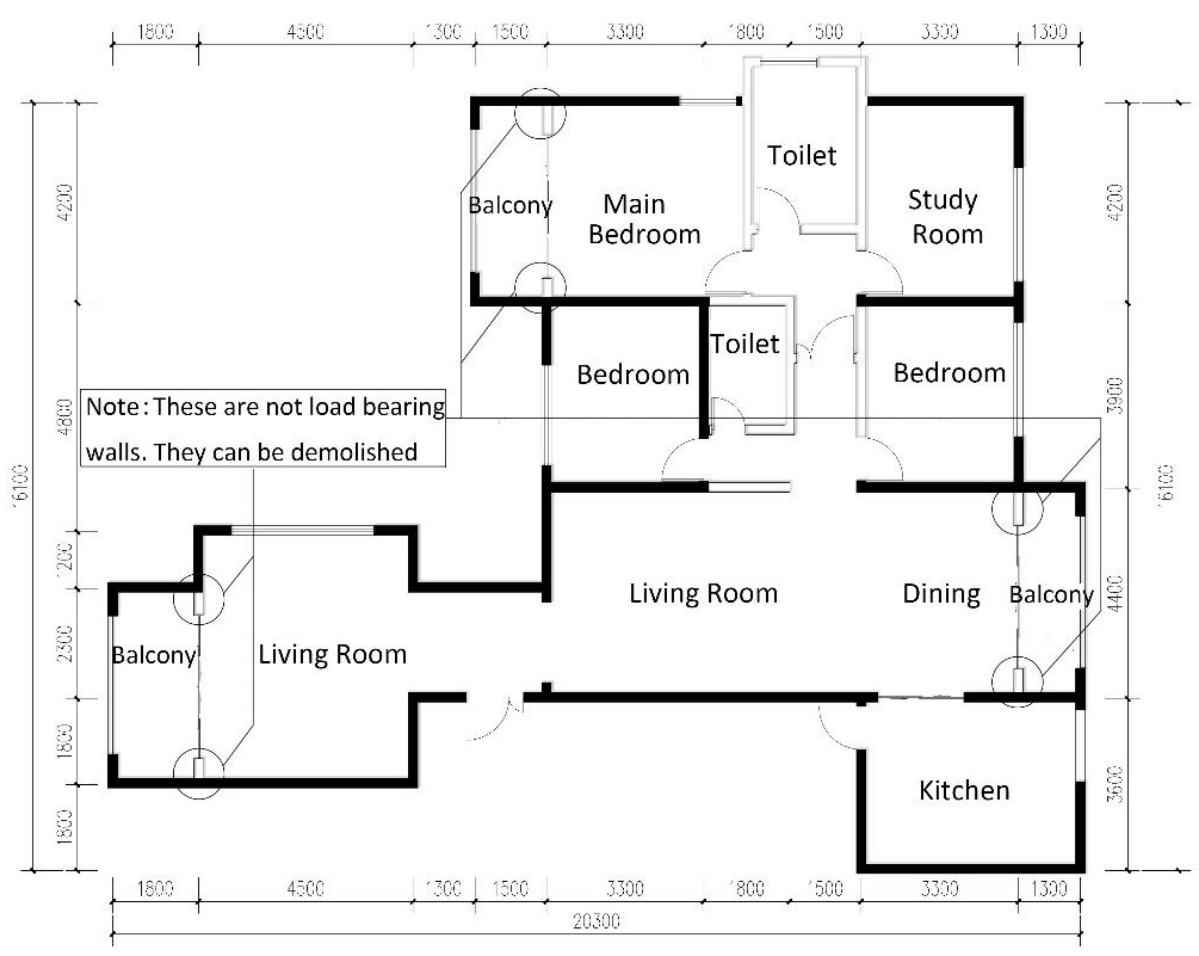


As part of the new rules and to prevent accidental loss of integrity of the load-bearing structure in the decoration process, householders needed to register with the property management company their refurbishment plans and pay a deposit of several thousand Chinese Yuan. They would then be given a plan of the apartment, which highlighted the load-bearing walls and non-load-bearing walls in the dwelling, and were asked to sign a contract not to demolish load-bearing structures. Once the decoration project was finished, the property management officer inspected the apartment and returned the deposit if everything had been done according to the regulation.

The many changes to design and fit-out are now incorporated into a basic working method, which enables satisfactory solutions to be developed; however, this does not address the whole picture.

\section{From Interior Design to Sustainability}

Though the risks and impacts on structural integrity were solved by the changes enacted, the whole process exposed the problem of a lack of any official regulations for a wide range of issues associated with interior fit-out and refurbishment projects. This occurred not only in private buildings, but also in commercial buildings. In particular, energy efficiency and sustainability codes are also missing; it would seem sensible to set up these and to provide more information to occupants and the general public. This could avoid waste and the use of inappropriate materials in these secondary phases of design and construction by the property owners and also introduce positive improvements according to the latest available practices, technologies and techniques. In considering the attitudes of those involved in this investigation, there would seem to be an appetite for offering such improvements.

The interview data and analysis of the interior design of apartments demonstrated two direct impacts. Firstly, demand for higher quality of life products increased; encouraged by rapid urbanisation and the availability of diverse styles of furniture, finishes and decoration materials in the marketplace. Householders became more knowledgeable about the functional potential of dwellings and required more sophistication in the designed space. The rising quality of life brought a broader range of family activities into use, and homes eventually became the place where people held parties and enjoyed other recreational activities, as well as places for study, work and receiving guests. The needs for natural light and ventilation with better environmental quality and distinctive features became stronger. The interviewees, despite coming from different social groups, all wished to decorate their homes to a standard that reflects a modernised lifestyle, to represent their personal understandings of their culture and to incorporate some ideas of "green" design.

Secondly, the interior design in commercial buildings provided examples and gave ideas to the home owners on how to decorate their own family spaces. Interior design and construction companies that were interviewed worked for both sectors, and their design models and use of technology and materials crossed the boundary between public and private buildings. They borrowed and introduced ideas from commercial settings, including spotlights, timber flooring, as well as new and unconventional decoration materials, such as metal, glass and plastic. The perceptions of materials used in the decoration/fit-out process also changed significantly, partly due to the influence of contemporary commercial interior design and consultants.

At the beginning of the housing reforms, the advice for interior design was that non-traditional materials, such as metal, stone, glass and plastic, were not suitable for family interior decoration, as they 
gave the impression of being cold, stiff and brittle; they also reflected light and made the internal environment "uncomfortable and unstable" [20]. However, increasingly, the commercial interior design sector seems to have influenced people's affective and cognitive preference in terms of ambience, design and layout.

Traditionally, designers followed principles focused on a southerly orientation and narrow plan, both of which can be incorporated into sustainable design. The distances between buildings were also designed to be the same as the building height to ensure that direct daylight was available as required by the building regulations. Solar hot water systems have also started to be much more widely used in recent years (Figure 10).

Figure 10. Solar hot water systems on roofs of residential apartments.

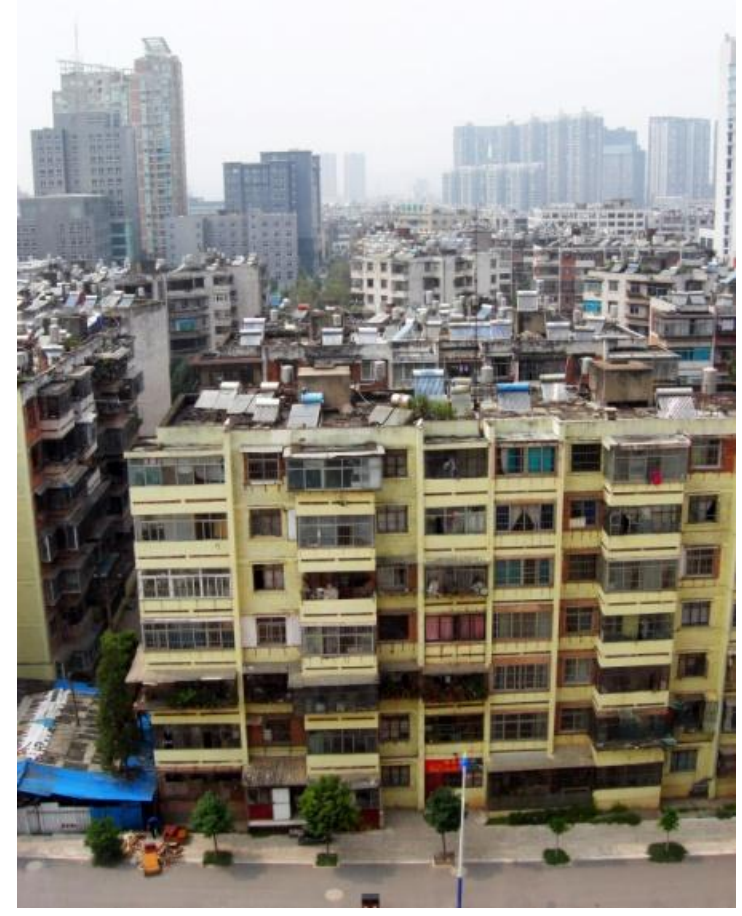

If designers are able to utilise more traditional techniques or adapt to changed circumstances and occupants are open to a range of degrees of change, too, then why not consider more advanced sustainable solutions and more ecological materials and technologies?

\section{Sustainability: Concepts and Perceptions}

\subsection{Introduction}

This study now proceeds to investigate the perception and understanding of the term "sustainable design" and associated issues by the interviewees involved in the study. Sustainability can have many connotations, and its translation is not widely used in China; in addition, many uses of sustainability refer to economic stability and longevity. This could link well to existing Chinese approaches: features in the past that were considered as an integral part of traditional design and construction included systematic planning and consideration of not only materials and spatial requirements, but also the changes in financial 
circumstances and family needs. In the Song Dynasty (960-1279), Yuan Chai discussed the effort and time spent to carefully design and construct a home in one's lifetime [21]. He considered that to build a house was a most difficult thing, but if this were properly prepared and planned, then a valuable and sustainable asset would be created for the family. These kinds of concerns are still reflected in the approaches taken in contemporary Chinese society in which the dwelling is an investment for the family and for the future.

Societal change, the faster pace of life and new building methods need different systematic approaches to achieve sustainable design in the present day. However, careful consideration of material choices, use over the longer-term, and the transitions during the building's life-time, together with the influence of the site context on design, which were common in the past, remain important today. Sustainable design theories, including the protection of the traditional heritage of a place and long-term planning, still apply in modern circumstances. These kinds of traditional knowledge and thought processes were evident in the responses of the interviewees as they discussed their wider perceptions. A summary of the information is provided in Table 1.

\subsection{Urban Issues}

Several interviewees mentioned their experience with large-scale construction of roads, bridges and building infrastructure during the 1990s along with the development of a number of residential estates. In order to accommodate such change, many Chinese cities, of which Kunming was one, demolished old neighbourhoods with the displacement of tens of thousands of residents from city centres to new residential zones. Many urban planners and architects were critical of the underlying master plan [17]. In the group discussion with local architectural lecturers, strong feelings were expressed about the disappearance of the old street patterns and residential housing, which occurred with such rapid speed. Some value was clearly attached to tradition by the interviewees and also to a slowing of the speed of change. This can both support and obstruct more sustainable design, which can take the beneficial aspects of traditional techniques, but which also needs to combine them in a necessarily short term with modern requirements and technologies.

\subsection{Interior Design Issues}

According to home owners, in a similar way to the rapid urban level changes, interior design and construction in private housing has tended to have little consideration for long-term planning. Householders, helped and prompted by the new decoration companies, commented that they had made quick decisions on the design, facilities and furniture choices; however, little information on the quality of the environment to be created or other long-term issues seems to have been provided to the interviewees. Potential changes and transitions over time were not considered until a later stage, and thus, a less than optimal solution resulted.

In the response regarding sustainable interior design, a number of interviewees, who reflected on their decisions about interior decoration, felt that they should have paid more attention to functional needs and the durability and quality of the facilities and furniture. Some of the facilities were difficult to replace once they were broken; for example, facilities in the bathroom and kitchen that were linked with water pipes and that were pre-fitted. 
They also felt that many design decisions were based on appearance rather than on function and the needs of daily life; this applied to such aspects as lighting, ventilation and circulation. They reported that advice should have been available on the quality of the space and durability of the facilities, rather than to focus solely on the styles of the interior design and for their advisors to have taken a more professional stance.

\subsection{Regulation}

A number of interviewees expressed the desire in one form or another to have a much more regulated system to ensure processes for construction followed suitable guidelines. There had been concerns about having to choose from catalogues and that what was installed did not always match their choice. Two responses in particular were critical of changes made by interior designers (such as a kitchen sink being located in a corridor in one and in the corner of the kitchen in another). These did not meet the requirements and were likely to create more waste in the future when changed again.

Yunnan Province published its own Design Standard for Energy Efficiency of Civil Buildings in November 2011 [22]. The Standard covers the thermal design and internal environment; it also covers the building envelope and water supply and drainage, electrical installations and has a brief section about renewable energy. Some interviewees felt that improved insulation and thermal mass of the building envelope were not important; for respondents based in Kunming, this may have been due to the fact that windows were frequently left open for much of the year. However, with the increasing demand for comfort and rising energy consumption, design details and materials, such as insulation and double glazing, ought to be promoted as important contributions to energy-saving and climate change mitigation. A stricter control system should be also set up to supervise and enforce the compliance rate in new construction.

\subsection{Green Products}

Interview data also demonstrated that people's perceptions of green products were linked more strongly to perceived healthy (organic) materials and a healthy environment, rather than specific issues, such as saving energy. The interviewees attached importance to sustainable development of bio-resources, as well as the protection of the natural environment, but less to the development of their own dwelling. The most notable comments observed in relation to public perception of sustainability were the favourable attention given to so-called "green" products, such as natural materials and sources of food, although one interviewee commented on the extra costs this could incur.

\subsection{Energy and Ventilation}

Solar panels have been widely installed on rooftops to provide hot water, and the findings suggested that a majority of the interviewees were able to use this to supply most of their needs. However, the interview data indicated that the saving of electrical energy and careful use of other resources, such as water, was not a priority in terms of what was considered to be a sustainable lifestyle. However, residents did comment on indoor thermal environments in winter and the lack of thermal insulation; all those interviewed used some kind of mobile heating apparatus in the winter. About half of the occupants used 
the heaters for most of time when the apartments were occupied, especially at night, and electricity bills increased substantially for the winter months.

A number of interviewees from all categories had the habit of leaving windows open when possible to encourage natural ventilation. For the residents of Kunming, there was also a perception that windows were left open at night to allow plenty of air exchange, due to the high altitude and lower oxygen concentrations compared to other cities. This would tend to indicate a gap in understanding of why a technique was used, even though natural ventilation could be seen as a sustainable approach in a suitable climate. Those interviewees with experience of a warmer and more variable climate in Hunan Province reported however that air-conditioners were widely used both in the summer and the winter, and there was no habit of opening the windows. The fit-outs and refurbishment/decoration styles and materials, however, were found to be very similar for all locations, and as suggested by other research, it seems likely that computer drawings for components and systems used in interior design are widely recycled and used in different regions regardless of local impacts, climate and circumstances [23].

Several responses were related to the poor performance of environmental control systems and the sense that neither the occupants nor the designers understood the potential outcomes of changes being made. There were positive responses, too, however - some commenting on the substantial improvement in internal comfort conditions. A skills shortage was also identified in those employed to install the changes-some interviewees commenting on the lack of general up-to-date knowledge and understanding.

\subsection{Role of Designers}

When asked about sustainable and green design specifically, interviewees were frequently critical of the knowledge of the designers and that they had needed to make further changes themselves to create a comfortable environment. It is perhaps the case that even experienced professionals lack knowledge of good environmental design techniques, though the education of the next generation may be better [24].

\subsection{External Design}

Some interviewees wanted to address changes to the outdoor space in order to create a buffer between the apartments and busy roads and to have more green space. One mentioned they considered it to represent being closer to nature and a (unpolluted) river. Some respondents did identify that reducing the use of resources, such as energy and water, was important, but this was a minority overall.

\subsection{Commentary}

The authors would argue that the successful integration of sustainability concepts and perceptions should be closely linked to an appreciation of the climate. They also believe the knowledge introduced into the design and construction marketplace through understanding gained by occupants/owners supported by design professionals with appropriate expertise to be important in dealing with some of the criticisms above. In Kunming, the location for most interviewees, architectural design emphasises natural daylight and natural ventilation, which seems to result in some energy saving and increased productivity, as well as comfort optimisation. However, following increasing demands for ever more comfortable environments 
found in the responses of interviewees, it will become more important to enhance the understanding of energy efficiency, both with the general public and with professional designers. Standards also need to be adjusted more carefully to local climate conditions.

\section{Discussion}

When privately owned housing first developed in China in the 1980s, the small sizes of rooms prevented the proper functional usage of the dwellings. New building space standard regulations eventually increased the room sizes from the 1980s onwards. The developing building regulations in China have allowed more methods for residential development to occur and to permit occupants, together with designers, to remodel their interior space with a high degree of freedom. This has accompanied the change in perception of the dwelling from a purely functional one, to one that is an expression of lifestyle and a tradable commodity.

Changing government policies and housing markets have combined to reshape the interior design and construction industry. The developments in the housing market have allowed architects to work closely with developers to put new design into practice. More diverse floor plans together with related structural changes, new technologies and materials have all emerged and had an impact over the period of focus in this paper. To meet the increasing demand of property owners to decorate the interior space according to their wishes, specialist design and decoration companies have emerged and have recently developed as an independent industry sector. New ways of managing the properties have also evolved rapidly. The commercialisation of interior design has had a significant influence on people's decision for choices within their private space at home.

In Kunming, it seems that the wide use of solar panel hot water systems and the relatively low energy consumption compared to other regions in the country have affected people's perception of sustainable design. Windows, often open all year round, have provided good natural ventilation, as well as daylight. The main concern from occupants in terms of sustainable interior design was the unhealthy airborne emissions from new furniture or new decoration. In Kunming, people's perception of green or sustainable design is a healthy environment that is close to nature.

Many standards and codes were issued in order to improve the energy efficiency of buildings, and other authors' research shows that buildings built after the 1990s are distinctly more energy efficient than before the 1990s [13]. However, less than 6\% of newly constructed buildings comply with these standards [25] and energy consumption for buildings in China is still 2-3-times higher than that of the developed countries with similar climatic conditions. Buildings are less comfortable as a result of poor thermal performance and too little insulation [26,27].

For the general public, the focus for sustainable interior space arose from a perception of providing a healthy environment and issues of indoor air quality, rather than reducing energy consumption. Users have become increasingly aware of potentially unhealthy emissions from paint and solvents used for furniture and internal decoration. It is normal practice to leave a newly decorated house fully open for ventilation for a few months before the inhabitants move in. People also try to buy natural products if they can afford the more expensive prices. Research suggests that "green" construction materials contribute to perceptions of a healthier and more productive environment [28]. Healthy materials and organic products are more expensive and are associated with an assumed better quality of life. 
In line with studies carried out in Western countries, barriers to energy efficiency in buildings include the fact that public awareness is low, and therefore, investors are not willing to pay higher initial costs, even though it would result in lower resource expenditures over the medium to long term [27]. However, as the research here demonstrates, the independent second stage design processes being carried out by the property owners (and their decisions on interior design) are perhaps more important than those from the developers in the first stage. Therefore, cost-reflective methods of analysis and more information should be given to users to increase public awareness, and educational campaigns aimed at holistic sustainability issues and building energy efficiency should be developed.

\section{Conclusions}

In the 1980s, when new government policies began to allow residential properties to be exchanged in the marketplace as commodities, the choice of dwelling types was limited, and there was little indication of whether a dwelling was designed well to meet users' requirements. The situation has changed fundamentally, and now, a wide range of dwelling types is available to meet the different requirements of homebuyers.

This study has explored the historical setting of housing development over several decades in an attempt to identify clear influencing factors and to determine the potential for enacting a more sustainable process for interior design and construction for dwellings in China. It investigated the development of residential apartment design under the influence of new government policies and building regulations and the availability of new design products, which have occurred since the 1980s. By interviewing a group of stakeholders, it has examined the historic and current process of design and construction of family interior space. The paper finds that the interior design industry has developed through collaboration between stakeholders and has discovered that a number of opportunities exist to effect positive change. It is also clear, however, that technologies aimed at lowering energy bills are not the priority for sustainable design for many stakeholders; their interests lie in a broader plane.

Through several different stages, transformation of dwelling design has occurred to meet more functional and aesthetic needs. This has been achieved by the combined forces of developers and design companies. In the process, different styles were explored to attract different buyers. Following the more relaxed government policy that encouraged the private ownership of housing, design companies have worked closely with developers to make new, but basic design types available in the market in a relatively short period. This evolution helped provide future potential for change; for instance, the modifications to load-bearing walls in the structure to allow owners to change the spatial arrangements. Improvements to the property management system have also ensured the safety of the practice.

From the top down, the government policy was to commercialise housing from the previous welfare system. The policy encouraged the construction and private sale of houses to solve housing shortage problems. After the 1990s, housing development also worked as a powerful sustaining feature of national economic development. From the bottom up, after gaining more individual freedom and private prosperity, home owners have had new opportunities to make decisions to change and refurbish their homes into their ideal cultural models. This has been partly hindered and partly supported by the information available. Initially, such information was limited and led to a focus on a narrow range of interior design 
companies who lacked in-depth knowledge and skills, but in more recent times, a better understanding seems to have developed, and more optimised outcomes have become possible.

Rapid urbanization has had significant impacts on residential, as well as family living patterns, which led to new residential housing and new social relationships. With the increasing urban population, modified traditional courtyard houses became overcrowded and people were happy to move to modern high-rise apartments. Therefore, the general public seems to have become more accepting of the clearance of such building types as part of the process of moving into new residential developments and the opportunities to develop their own interior design variations.

The contemporary public media introduced ideas of new lifestyle and design possibilities from around the world to China, and this has been particularly adopted in the fit-out and refurbishment of apartments. Design companies, developers and property management companies seem to have not only learned from developed countries about new ideas, but also successfully adapted these ideas to Chinese users. Larger living spaces, larger windows, sophisticated lighting systems, timber floors and colourful furniture, together with expensively installed bathroom facilities, have all brought new environments into people's lives where it could be afforded, although not always in optimised forms.

In the present day, with the help from the design and construction companies, a family can normally undertake the fit-out/decoration of an apartment over a three- to four-month time period. However, occupants, who drive these modifications, may not have sufficient awareness of sustainability other than through a narrow range of themes, often associated with products and lifestyles considered as being "green". Based on the interviews carried out, the understanding of climate and site or other features of the design and construction that previous generations had are less prevalent in the present day, and as a result, optimisation of dwelling sustainability is less than perfect and leaves open some risks for the future.

Overall, this paper makes four important contributions to the discussion of sustainable architectural design in China:

- It is the first time that the interior fit-out stage for dwelling design has been identified as an important phase of construction in which it would be possible to improve design efficiency and reduce waste. This has previously been overlooked by building regulation and government policy;

- It was also found that both the public and professionals are lacking in awareness of sustainable technologies and associated techniques;

- It has exposed a better understanding of how structural changes to dwellings were implemented through the co-operation of the property owners, designers and developers;

- It has shown that, over the period in which housing became a market commodity, the implementation of sustainable measures has not worked well in China by merely relying on a top-down implementation of standards and codes. In fact, important co-operation between stakeholders happened when there was no regulation or requirement from the government.

As a result, the authors advocate several measures to help improve the sustainability of dwellings:

(1) The second (refurbishment or interior design) phase of housing occupancy needs to be provided with suitable building regulations in order to ensure that construction meets the standard intended by the regulations for the initial construction phase; 
(2) There is need for a validated and accepted form of building development assessment technique that can evaluate more quantitatively the benefits, or otherwise, of different design and construction options and that also balances subjective opinions with broader analysis;

(3) There needs to be more distribution of better quality information to aid the understanding of occupants and to provide knowledge on the implications of the choices they make in completing the interior design stage of their dwellings;

(4) Although at present, in some locations in China, energy use in the dwelling is not considered an important issue, as costs for energy increase and demands for pollution control evolve and as occupants' expectations for better comfort standards develop, energy issues are likely to become more important. It is therefore vital that techniques to optimise the energy-efficient design of dwellings are developed and communicated, particularly to professionals and other key stakeholders.

There are reasons to feel confident that these changes can be pursued in the same way that changes to load-bearing walls and the implementation of associated management rules were able to reduce the negative consequences of some interior design actions. Improvements to encourage broader sustainable design can also occur through appropriate collaboration between stakeholders and with enforcement by the policy makers.

It is recognised that the number of people involved in scoping and detailed interviews and their location imposes some limits on the influence of the study; however, it would not be possible at the current time to carry out numerous interviews in each province of China, and in any case, it was not the aim to derive a national database. The purpose has been to glean information on evident circumstances impacting dwelling procurement, construction and use and to determine where further research is required. Wherever possible, the issues related to the city of study have been placed in the wider context, and also, use has been made of respondents with experience with other cities and climates. It therefore provides valid data that may be used to leverage support for larger-scale studies and certainly studies of the key themes identified.

\section{Acknowledgments}

The authors acknowledge the time given freely by various stakeholders and interviewees in order to provide the basis of the analysis presented. The access to drawings, both historic and contemporary, from official bodies and from designers and occupants is also acknowledged.

\section{Author Contributions}

Each author has contributed equally to the development and writing of the paper. The drawings and photographs included in this paper have been devised and provided by the authors.

\section{Conflicts of Interest}

The authors declare no conflict of interest. 


\section{References}

1. The Economic Observer. China Home Ownership Reaches 90\%, 16 May 2012. Available online: http://eeo.com.cn/ens/2012/0516/226534.shtml (accessed on 4 October 2014).

2. Yang, L.; Wang, Y. The Housing Reform: Theoretical Introspection and Realistic Selection; Tianjin People's Publishing House: Tianjin, China, 1992.

3. Li, S.; Huang, Y. Urban housing in China: Market transition, housing mobility and neighbourhood change. Hous. Stud. 2006, 21, 613-623.

4. Chen, J.; Guo, F.; Wu, Y. One decade of urban housing reform in china: Urban housing price dynamics and the role of migration and urbanization, 1995-2005. Habitat Int. 2011, 35, 1-8.

5. Wu, F. Changes in the structure of public housing provision in urban China. Urban Stud. 1996, 33, 1601-1627.

6. Yang, X. Household registration, economic reform and migration. Int. Migr. Rev. 1993, 27, 796-818.

7. Kojima, R. Urbanization in China. Dev. Econ. 1995, 33, 121-154.

8. Yeung, Y.; Shen, J. Developing China's West: A Critical Path to Balanced National Development; Hong Kong Chinese University Press: Hong Kong, 2004.

9. Lin, G.C.S.; Ho, S.P.S. The state, land system, and land development processes in contemporary China. Ann. Assoc. Am. Geogr. 2007, 95, 411-436.

10. Li, S.; Zhen, Y. The road to homeownership under market transition: Beijing, 1980-2001. Urban Aff. Rev. 2007, 42, 342-368.

11. Lv, J.; Peter, G.R.; Zhang, J. Modern Urban Housing in China 1840-2000; Prestel: New York, NY, USA, 2001.

12. Zheng, N.; Hu, H. Our opinion on high-rise residential buildings. J. Archit. 1981, 3, 40-42.

13. $\mathrm{Hu}, \mathrm{T}$;; Yoshino, H. Analysis on energy consumption and indoor environment in Kunming, China. Sustainability 2012, 4, 2574-2585.

14. Zhang, H.; Yoshino, H. Analysis of indoor humidity environment in Chinese residential buildings. Build. Environ. 2010, 45, 2132-2140.

15. Yoshino, H.; Yoshino, Y.; Zhang, Q.; Mochida, A.; Li, N.; Li, Z.; Miyasaka, H. Indoor thermal environment and energy saving for urban residential buildings in China. Energy Build. 2006, 38, 1308-1319.

16. Wang, Y.P.; Murie, A. Commercial housing development in urban China. Urban Stud. 1999, 36, 1475-1494.

17. Zhang, L. Spatial modernity in late-socialist China. Curr. Anthropol. 2006, 47, 461-484.

18. Li, S.M. Housing tenure and residential mobility in urban China a study of commodity housing development in Beijing and Guangzhou. Urban Aff. Rev. 2003, 38, 510-534.

19. Dai, G.; Bao, J. Spatial distribution of integrated impact index of mega-event-A case study of Expo'99 Kunming. Chin. Geogr. Sci. 2008, 18, 214-223.

20. Bai, S. Interior decoration and furnishing in residential rooms. Decoration 1995, 3, 7-8. (in Chinese).

21. Ebrey, P. Family and Property in Sung China: Yuan Ts'ai's Precepts for Social Life; Princeton University Press: Princeton, NJ, USA, 1984. 
22. Design Standard for Energy Efficiency of Civil Buildings; DBJ 53-XXX-201X; Yunnan Provincial Department of Housing and Urban-Rural Development (YPDHURD): Kunming, China, 2011.

23. Han, J.; Margalit, H. Imagining modernity through architecture in contemporary China. Int. J. Des. Soc. 2013, 7, 29-38.

24. Pitts, A. Prevalence and Evaluation of Bioclimatic Design Techniques Used to Achieve Low Energy Comfort in Architectural Design Proposals. In Proceedings of the 8th Windsor Conference: Counting the Cost of Comfort in a Changing World, Windsor, UK, 10-13 April 2014.

25. Jiang, K.; Hu, X. Energy demand and emissions in 2030 in China: Scenarios and policy options. Environ. Econ. Policy Stud. 2006, 7, 232-250.

26. Li, B.; Yao, R. Urbanisation and its impact on building energy consumption and efficiency in China. Renew. Energy 2009, 34, 1994-1998.

27. Chmutina, K. Building Energy Consumption and Its Regulations in China, Discussion Paper 67; China Policy Institute, The University of Nottingham: Nottingham, UK, 2010.

28. Langer, K.; Watson, R. The greening of China's building industry. China Bus. Rev. 2004, 31, 56.

(C) 2014 by the authors; licensee MDPI, Basel, Switzerland. This article is an open access article distributed under the terms and conditions of the Creative Commons Attribution license (http://creativecommons.org/licenses/by/4.0/). 